\title{
Research into the Talent Development Mode for Collaborated School Running Between Enterprises and Agricultural Institutions of Higher Learning
}

\author{
Hailong SHAO ${ }^{1, a}$, Dongju DU ${ }^{2, b}$
}

${ }^{1}$ College of Engineering and Technology, Jilin Agricultural University, Changchun, 130118, China

${ }^{2}$ College of Animal Science and Technology, Jilin Agricultural University, Changchun, 130118, China

aemail: shaohailong1992@126.com, bemail:473352805@qq.com

\begin{abstract}
Keywords: Agricultural Institutions of Higher Learning; School-enterprise Collaborated School Running;Talent Development Mode
\end{abstract}

\begin{abstract}
School-enterprise collaborated school-running is an efficient approach for enterprises to conduct continuing education and for schools to implement practical teaching. Agricultural institutions of higher learning have subsequently established flexible and diversified partnership with enterprises. Despite of favorable results already achieved, there are many problems, such as backward development concepts and mechanisms, difficulty of efficiently implementing practical links, shortage of highly qualified faculty and lack of entrepreneurship textbooks and courses.
\end{abstract}

\section{Introduction}

The talent development of school-enterprise collaborated school running is applied, practical and open. To emphasize on integration of enterprises' competitive resources during the exploration of the talent development mode for school-enterprise collaborated school running is an efficient approach to promote sustainable development of China's institutions of higher learning.

\section{Problems existing in the traditional talent development mode}

Emphasis on theories and ignorance of practices

At present, many institutions of higher learning in China attach great importance to theoretical course teaching. Practical teaching is ignored for various reasons. Due to lack of practice platforms, students have rare opportunities to enter enterprises, participating in their operation and management and experiencing the entrepreneurial process. As a result, theoretical teaching and practical teaching is disjointed, and the practical effects are far from satisfaction. The main cause of this is that agricultural institutions of higher learning lack a practical support system and resources which can be coordinated and utilized, and that a scientific, efficiently, mutually-supporting and multilaterally-promoting operation mechanism has not yet taken shape $\mathrm{e}^{[1]}$.

Lack of faculty

Living and working experiences of the faculty can directly influence the effect of classroom teaching. Most teachers in Chinese institutions of higher learning belong to the "academism." Lecturers mostly lack entrepreneurial experiences. Though efforts have been made to enhance practicability and targeted nature of education innovation by inviting a large number of entrepreneurs as guest professors, most of these courses are conducted in the form of lectures. A system has not yet been formed. Compounded by lack of organizing, coordination, institutional guarantee and capital support, many entrepreneurs invited lack teaching experiences, and there is a great room for improvement of their teaching effects.

Lack of a guarantee system

School-enterprise collaborated school running and talent development is a systematic project, calling for collaboration of the government, enterprises and schools to ensure its steady development and realization of practical effects. Currently, institutions of higher learning play a 
dominant role in China's agricultural education. Various elements involved in agricultural education are scattered and isolated, having not yet formed a real resultant force. In recent year, the government has provided guidance and help for entrepreneurship of college students in terms of policies, funds, information and platform building. However, the follow-up support and guarantee are still inadequate. Enterprises have not yet been active enough to participate in education innovation of institutions of higher learning. A favorable cultural atmosphere featuring wide attention and vigorous support to and for college students' entrepreneurship has not yet been created $^{[2]}$.

School-enterprise collaborated talent development is based on all-around development of students. Realization of students' subjectivity and individual potential is its fundamental goal. Emphasis should be laid on organic combination and synchronous improvement of basic entrepreneurial qualities and abilities, including innovational spirit and entrepreneurship. School-enterprise collaborated talent development should be practical, open and practical.

\section{Establishment of the school-enterprise collaborated talent development mode}

The school-enterprise collaborated school running process is an interaction and coordination process between institutions of higher learning and enterprises. School-enterprise collaborated school running is a cooperative game. There should be valid and binding agreements clinched to certify the formation of the commercial partnership, and such agreements should reflect win-win cooperation and maximization of collective interests. [1] School-enterprise collaborated school running and talent development is to deeply integrate competitive resources of both sides through open school running and market-oriented operation. It highlights basic characteristics of cooperation to achieve development, bring up talents and improve school running. Interaction between schools and enterprises can generate an innovational talent development mechanism so as to develop students' internal qualities, optimize their entrepreneurial thinking and enable students to make special contributions to economic and social development.

Establishment of a win-win and mutually beneficial school-enterprise cooperation mechanism

The key to improving talent development of school-enterprise collaborated school running lies in stimulation of enterprises' motivation, initiative and enthusiasm, and optimization of the operation mechanism for enterprises to participate in the whole process of innovational talent development. School-enterprise collaborated school running under the market economic conditions is not only educational cooperation, but also economic cooperation based on principles of mutual benefits and equality. Both parties are major market players, and have their own objectives and motivation. [2] To institutions of higher learning, collaborated talent development can save resource cost, expand school running paths and enrich school running characteristics. To enterprises, collaborated talent development can bring up to them talents with innovational and entrepreneurial qualities, thus increasing their reputation and improving their competitiveness. With the market as the bond, a win-win cooperation mechanism based on equality, free will and mutual benefits is a fundamental path to promote in-depth and sustainable development of school-enterprise school running, and a key to efficiently stimulating development momentum of enterprises ${ }^{[3]}$.

Enterprises in the leading place and students as subjects

The traditional education features course instruction. Its teaching and operation system emphasizes on students' unconditional obedience to the existing courses. As a result, courses are dull and offer few options. The learning content fails to keep up with times. To solve the problem, enterprises should be introduced together with their competitive resources to participate in the whole process of talent development. Thus, the rigid talent development mechanism can be turned into a flexible one. The education innovation and management functions and decision-making right should be delegated to education management institutions jointly founded by schools and enterprises, and a faculty team and teaching management team with enterprises at the core should also be jointly built. This can help reduce management hierarchy, overcome overlapping and low efficiency of traditional educational management modes, and efficiently integrate and reasonably distribute corporate resources, promote combination of school management culture and corporate 
management culture. In this way, the management efficiency of both sides can be improved.

Formulation of a diversified course teaching system

The course system is a specific reflection of professional objectives after decomposition, a major carrier to implement talent development and a key to improving the talent development quality. In terms of curriculum construction for school-enterprise collaborated school running, the most important thing is to build the curriculum development mode, the modular structure and the core teaching methods. First, proceeding from social demands, individual development and educational rules, the talent development objectives, specifications and requirements should be scientifically set, and education innovation should be integrated into the whole education system to form an organic connection with the professional subject education and to realize diversity of development modes and personalization of development plans. Second, establish a three-dimensional, systematic and comprehensive innovational education curriculum module. Attention should be paid to the project-based curriculum system and framework principle of knowledge application and technical transfer. Based on academic subjects, diversity and practicality of the curriculum setting should be enhanced. Third, find out core teaching methods for in-depth participation of enterprises. Emphasis should be paid to systematicness, practicality and practicalness as well close combination of practical problems confronting enterprises and skills required by entrepreneurship. Besides, teaching reform should be conducted so as to encourage students to deeply participate in practical learning in enterprises. Besides, case study, interactive teaching, simulated entrepreneurship and other teaching strategies of the kind can be introduced. Relying on the local practice bases, schools can enhance intensity of their practical teaching, and realize mutual connection and support between the course system and the relevant skill platforms and practical teaching platforms ${ }^{[4]}$.

Establishment of a diversified talent development evaluation index system

Talent development evaluation is an important link of the whole talent development process. Some scholars point out that agricultural education in institutions of higher learning is subjective to the influence of multiple factors. Therefore, it is impractical and meaningless to build a unified evaluation index system. Diversity of objectives of China's education, hierarchy of the implementation process, diversity of the evaluation subject and the time-lag effect of education should all be taken into consideration, and evaluation indexes and evaluation processes should be reasonably designed according to different demands. [3] Thus, it can be seen that talent development evaluation of school-enterprise collaborated school running should account for both internal and external indexes, short-term and long-term indexes. Combining basic characteristics of school-enterprise school running, a diversified modularized index system can take shape. First, through diverse investigation and systematic analysis, enterprises and schools can formulate feasible evaluation plans so as to guarantee orderly progress of key links, including evaluation standards, content and procedures ${ }^{[5]}$. Second, establish evaluation standards for school-enterprise school running effects, and form a scientific and diversified evaluation standard system with both quantitative statistics and qualitative evaluation.

Completesecurity system

First, the government should formulate and improve variously supporting policies, and enhance the guarantee of school-enterprise collaborated school running in terms of funds, institutions and laws. Besides, the government should emphasize on creation of the cultural atmosphere and the opinion atmosphere. Second, enterprises should give full play to their capital advantages, assisting schools in building investment funds and supporting and nurturing a batch of excellent students'entrepreneurial projects. Their human resource advantages should also be capitalized on. Excellent entrepreneurs, investors and venture capitalists can be invited to be entrepreneurial supervisors to help students take fewer twists and turns on their entrepreneurial path. Third, schools should formulate motivational entrepreneurial policies, create a free entrepreneurial environment advocating entrepreneurship and tolerating failures, highlight the value orientation and campus culture with entrepreneurship at the core and demonstrate the educational concept of developing entrepreneurial talents in institutions of higher learning. 


\section{Conclusion}

School-enterprise collaborated school running is of far-reaching significance to enterprises and schools. Recent practices have proved that school-enterprise collaborated school running is an efficient approach to achieve resource sharing and win-win results between enterprises and schools.

\section{References}

[1] FANG Deying. School-Enterprise Cooperation Innovation-Game, Evolution and Countermeasures[M]. Beijing: China Economic Press, 2007: 82-83.

[2] SHEN Yunci. Problems Facing School-enterprise Cooperation and Countermeasures from the Perspective of Market Economy[J]. China Higher Education, 2010, (Z3): 42-44.

[3] NIU Changsong. Entrepreneurship Education Studies in British Institutions of Higher Learning[M]. Shanghai: Xuelin Press, 2009:51.

[4] SUN Xingmin, YANG Naitong. Theory and Practice of School Enterprise Cooperation in Running a School[J]. Journal of Hebei Engineering and Technical College,2013(1).

[5] SHI Yida, DI Dongtao. Rational Thinking on the Mode of School Enterprise Cooperation in Running a School[J]. Communication of Vocational Education,2010(2) 